\title{
EFEKTIVITAS MODEL BLENDED LEARNING TERHADAP MOTIVASI DAN TINGKAT PEMAHAMAN MAHASISWA MATA KULIAH ALGORITMA DAN PEMROGRAMAN
}

\author{
Sarah Bibi \\ IKIP PGRI Pontianak \\ s.bibbib@gmail.com \\ Handaru Jati \\ Universitas Negeri Yogyakarta \\ handaru@uny.ac.id
}

\begin{abstract}
Abstrak
Penelitian ini bertujuan untuk (1) mengetahui perbedaan motivasi dan tingkat pemahaman mahasiswa antara pembelajaran model blended learning dengan pembelajaran konvensional, dan (2) mengetahui peningkatan motivasi dan tingkat pemahaman mahasiswa akibat penerapan pembelajaran model blended learning. Jenis penelitian ini adalah quasi experimental. Populasi penelitian adalah mahasiswa semester 2 tahun ajaran 2013/2014 Program Studi Pendidikan Teknologi Informasi dan Komputer STKIP PGRI Pontianak yang berjumlah sebanyak 270 mahasiswa. Penentuan sampel menggunakan teknik purposive sampling berjumlah 156 mahasiswa. Pengumpulan data menggunakan tes soal berbentuk pilihan ganda dan angket, teknik analisis data yang digunakan adalah statistik parametrik uji-t dengan taraf signifikansi 0,05. Hasil penelitian ini menunjukkan bahwa (1) terdapat perbedaan motivasi belajar mahasiswa antara pembelajaran model blended learning dengan pembelajaran konvensional sebesar 5,782 dan terdapat perbedaan tingkat pemahaman sebesar 9,935 serta (2) ada peningkatan motivasi belajar mahasiswa akibat penerapan pembelajaran model blended learning rata-rata peningkatan 11,705 dan ada peningkatan pemahaman mahasiswa rata-rata peningkatan 30,288.
\end{abstract}

Kata kunci: Blended Learning, konvensional, motivasi, tingkat pemahaman.

\section{THE EFFECTS OF BLENDED LEARNING MODEL ON THE STUDENT'S MOTIVATION AND UNDERSTANDING ON THE SUBJECT OF ALGORITHMS AND PROGRAMMING}

\begin{abstract}
This research aims (1) to determine the differences in motivation and understanding level of the students between learning model of blended learning and the conventional, and (2) the improvement of students learning motivation and understanding due to the use of blended learning model.This research was a quasi-experimental. The population is the second semester students of the academic year 2013/2014 Study Program Computer and Information Technology Department of Teacher Training and Education PGRI Pontianak as many as 270 students. The selection of the sample of students was done using purposive sampling technique as many as 156 students. Collecting data using test multiple-choice and questionnaire, the data analysis techniques used were statistical parametric t-test with a significance level of 0.05. The results of the research show that (1) there is a difference in learning motivation of the students between learning model of blended learning and conventional learning of 5.782 and there is difference in the understanding level of the students of 9.935 and (2) there is an improvement in learning motivation of the students due to blended learning application with an average of 11.705 and there is an improvement in the understanding level of the student with an average of 30.288 .
\end{abstract}

Keywords: Blended Learning, conventional, motivation, understanding level. 


\section{PENDAHULUAN}

Kemajuan ilmu pengetahuan dan teknologi dalam berbagai bidang kehidupan membawa perubahan, terutama dalam peningkatkan mutu pendidikan. Banyak faktor yang mempengaruhi perkembangan pendidikan di masa mendatang, di antaranya adalah perkembangan teknologi informasi yang pesat serta persaingan yang semakin ketat dalam memperoleh lapangan pekerjaan yang ditandai dengan ciri-ciri berkembangnya teknologi baru yang menuntut peningkatan kompetensi. Dalam konteks inilah, pembaruan dalam bidang pendidikan dan pembelajaran perlu dilakukan terus-menerus dan harus merupakan suatu proses yang tidak pernah berhenti (never ending process). Pendidikan dan pembelajaran yang berbasiskan pada kompetensi merupakan contoh dari hasil perubahan dengan tujuan meningkatkan kualitas pendidikan dan pembelajaran.

Pembangunan dalam bidang pendidikan diamanatkan dalam Undang-undang Nomor 20 Tahun 2003 Pasal 3 tentang Sistem Pendidikan Nasional (Sisdiknas) bahwa pendidikan nasional berfungsi mengembangkan kemampuan dan membentuk watak serta peradaban bangsa yang bermartabat dalam rangka mencerdaskan kehidupan bangsa, bertujuan untuk mengembangkan potensi peserta didik agar menjadi manusia yang beriman dan bertakwa kepada Tuhan Yang Maha Esa, berakhlak mulia, sehat berilmu, cakap kreatif, mandiri dan menjadi warga negara yang demokratis serta bertanggung jawab.

Memahami makna dari sistem pendidikan nasional adalah amanat yang mengandung pesan moral sebagai landasan penyelenggaraan pendidikan dan sarana pencapaian citacita perjuangan dalam peradaban Bangsa Indonesia. Pendidikan kejuruan adalah jenjang pendidikan yang merupakan bagian dari sistem pendidikan nasional yang berhubungan dengan mempersiapkan seseorang untuk bekerja dan dengan memperbaiki pelatihan potensi tenaga kerja. Pendidikan kejuruan bertujuan mempersiapkan tenaga kerja yang memiliki keterampilan dan pengetahuan sesuai dengan kebutuhan persyaratan lapangan kerja dan mampu mengembangkan potensi dirinya dalam menerima dan beradaptasi dengan perkembangan teknologi. Dalam proses pendidikan kejuruan perlu ditanamkan pada mahasiswa pentingnya penguasaan pengetahuan dan teknologi, keterampilan bekerja, sikap mandiri, efektif dan efisien dan pentingnya keinginan sukses dalam karimya sepanjang hayat.

Program Studi Pendidikan Teknologi Informasi dan Komputer STKIP PGRI Pontianak memiliki tujuan yang sama, yaitu menghasilkan lulusan yang merupakan tenaga terdidik, terlatih dan terampil, yang memenuhi kompetensi yang dipersyaratkan oleh dunia kerja dalam bidang pendidikan yang relevan serta memiliki wawasan yang luas tentang perkembangan dunia pendidikan. Keberhasilan lulusan salah satunya ditentukan oleh keberhasilan proses belajar mengajar.

Kompetensi yang harus dimiliki mahasiswa program studi pendidikan teknologi informasi dan komputer adalah menguasai mata kuliah algoritma dan pemrograman. Mata kuliah Algoritma dan Pemrograman merupakan salah satu mata kuliah prasyarat yang harus ditempuh oleh mahasiswa Program Studi Pendidikan Teknologi Informasi dan Komputer STKIP PGRI Pontianak. Algoritma merupakan langkah-langkah logis penyelesaian masalah yang disusun secara sistematis berdasar dari masalah yang akan diselesaikan. Dalam bidang komputer, algoritma sangat diperlukan dalam menyelesaikan berbagai masalah pemrograman, tanpa algoritma yang dirancang dengan baik maka proses pemrograman akan menjadi salah, rusak, atau lambat dan tidak efisien. Selain itu, kemahiran dalam pemrograman membutuhkan kemampuan berpikir, seperti analisis, desain, pemikiran analogis, evaluasi, dan refleksi (Hadjerrouit, 2007, p.286).

Pencapaian kompetensi mahasiswa dalam proses pembelajaran maka digunakan beberapa pendekatan model pembelajaran. Model pembelajaran yang selama ini dilakukan adalah dengan model pembalajaran konvensional. Pada model ini sering disebut sebagai "Teacher Centred Learning" yang meletakkan dosen sebagai pelaku/subjek dan mahasiswa sebagai objek. Pandangan-pandangan untuk mengubah Teacher-centred Learning menjadi Studentcentred Learning sangat didukung dengan 
adanya perkembangan teknologi informasi yang demikian pesat. Student Centered Learning adalah suatu model pembelajaran yang menempatkan mahasiswa sebagai pusat dari proses belajar, mahasiswa diharapkan aktif dan mandiri dalam proses belajarnya, yang bertanggung jawab dan berinisiatif untuk mengenali kebutuhan belajarnya, menemukan sumber-sumber informasi untuk dapat menjawab kebutuhannya, membangun serta mempresentasikan pengetahuannya berdasarkan kebutuhan dan sumber-sumber yang ditemukannya. Disisi lain, para dosen beralih fungsi dari pengajar menjadi mitra pembelajaran maupun sebagai fasilitator (from mentor in the center to guide on the side).

Dalam proses pendidikan khususnya proses belajar mengajar, dosen melakukan proses pembelajaran dengan mempertimbangkan penggunaan model pembelajaran yang sesuai dengan karakteristik mata kuliah. Pemilihan model pembelajaran yang digunakan berpengaruh terhadap kualitas dan hasil pembelajaran. Sistem pembelajaran yang baik menuntut adanya pengembangan, perbaikan dan perubahan sepanjang masa.

Seiring dengan perkembangan teknologi yang ada, implementasi dari pemanfaatan internet untuk pembelajaran salah satunya adalah e-learning. E-learning atau Internet enable learning menggabungkan metode pengajaran dan teknologi sebagai sarana dalam belajar. Definisi e-learning adalah proses belajar secara efektif yang dihasilkan dengan cara menggabungkan penyampaian materi secara digital yang terdiri dari dukungan dan layanan dalam belajar (Barbara, et al, 2008, p.4). Pendapat lain juga dikemukan oleh Seok (2008, p.5) menyatakan bahwa "e-learning is a new form of pedagogy for learning in the $21{ }^{\text {st }}$ century. E-Teachers are e-learning instructional designer, facilitator of interaction and subject matter experts". Kelebihan e-learning dapat memberikan fleksibilitas, interaktifitas, kecepatan dan visualisasi melalui berbagai kelebihan dari masing-masing teknologi. Selanjutnya dikenal pula istilah blended learning (hybrid learning) secara sederhana dapat didefinisikan sebagai perpaduan metode belajar tatap muka (di dalam kelas) dengan materi yang diberikan secara online.

Blended learning tidak sepenuhnya pembelajaran dilakukan secara online yang menggantikan pembelajaran tatap muka di kelas, tetapi untuk melengkapi dan mengatasi materi yang belum tersampaikan pada pembelajaran saat mahasiswa belajar di kelas. Menurut Bonk dan Graham (2006, p.5) mendefinikan kombinasi dari e-Learning dan pembelajaran tatap muka dikelas sebagai berikut :

Blended learning is the combination of instruction from two historically separate models of teaching and learning: Traditional learning systems and distributed learning systems. It emphasizes the central role of computer- based technologies in blended learning.

Dosen menggunakan teknologi komputer dengan akses internet dalam menyediakan informasi, bahan bacaan, dan materi kuliah untuk mahasiswa. Beberapa dosen memungkinkan mahasiswa untuk berinteraksi satu sama lain dengan menggunakan teknologi komunikasi asynchronous dan synchronous. Komunikasi asynchronous didefinisikan sebagai instruksi atau komunikasi yang berlangsung diwaktu yang berbeda dan lokasi yang berbeda (Fenton \& Watkins, 2010, p.233). Komunikasi synchronous didefinisikan sebagai instruksi atau komunikasi yang terjadi secara real time, dimana mahasiswa dan dosen berada pada waktu yang sama serta kemungkinan besar dari berbagai lokasi (Fenton \& Watkins, 2010, p.240).

Beberapa studi penelitian telah menemukan bahwa blended learning dapat meningkatkan hasil belajar sama dengan atau lebih tinggi dari mahasiswa yang belajar secara konvensional atau sepenuhnya online, meskipun tingkat keberhasilan bervariasi antara disiplin ilmu (Heinze, 2008, p.35). Oleh karena itu tidak mengherankan bahwa banyak sekolah-sekolah ataupun perguruan tinggi telah menerapkan atau mempertimbangkan model blended learning. Hal tersebut juga didukung oleh pendapat Graham (2006, p.7) yang mengemukakan: "we can be pretty certain that the trend toward blended 
learning systems will increase". Namun, harus diperhatikan bahwa keberhasilan blended learning tidak terjadi secara otomatis, faktor utama dalam keberhasialan blended learning yaitu mempertimbangkan pedagogi dan desain instruksional terkait dengan cara terbaik untuk memanfaatkan alat-alat teknologi, bagaimana memfasilitasi interaksi antara mahasiswa, cara memotivasi mahasiswa, serta mangatur materi yang terbaik disampaikan melalui Internet dibandingkan tatap muka.

Penerapan blended learning dapat memberikan minat belajar mandiri mahasiswa karena banyak informasi mutakhir yang dapat diperoleh melalui internet, metode ini sangat efisien karena selain mahasiswa bisa mendapatkan perkuliahan tatap muka dengan dosen di dalam kelas, mereka juga bisa mengakses materi yang diberikan secara online di manapun mereka berada. Blended Learning sangat bermanfaat untuk mengembangkan dan menanamkan keterlibatan mahasiswa akan perkuliahan yang diadakan karena mahasiswa harus aktif mengikuti perkembangan yang terjadi di dalam kampusnya.

Perubahan tingkah laku yang timbul akibat proses belajar adalah sebagai bentuk dari perubahan pemahaman perilaku, persepsi, motivasi, atau gabungan dari semuanya dan kualitas belajar seseorang ditentukan oleh pengalaman-pengalaman yang diperolehnya saat berinteraksi dengan lingkungan sekitarnya (Winataputra, 2008, p.5).

Hakikat motivasi belajar adalah dorongan internal dan eksternal pada pembelajar untuk mengadakan perubahan tingkah laku yang mempengaruhi keberhasilan seseorang dalam belajar. Motivasi sendiri mempunyai peranan dalam membantu memahami dan menjelaskan perilaku individu dalam belajar. Peranan penting motivasi dalam belajar antara lain menentukan hal-hal yang dianggap dapat menguatkan kegiatan belajar dan memperjelas tujuan belajar. Tujuan dari pembelajaran adalah membantu pembelajar agar memperoleh berbagai pengalaman sehingga pengetahuan, keterampilan, dan nilai atau norma yang mengendalikan sikap dan perilaku siswa mengalami perubahan secara positif baik kualitas maupun kuantitas (Uno, 2013, p.27).
Berdasarkan pengamatan terhadap proses belajar mengajar di Program Studi Pendidikan Teknologi Informasi dan Komputer Sekolah Tinggi Keguruan dan Ilmu Pendidikan (STKIP) PGRI Pontianak, proses belajar mengajar pada mata kuliah algoritma dan pemrograman menggunakan pola-pola konvensional antara dosen dan mahasiswa dalam jumlah tertentu, ujian tertulis, serta kehadiran siswa dalam kelas masih dianggap sebagai pemicu keberhasilan pembelajaran. Partisipasi mahasiswa relatif rendah, dalam proses pembelajaran dosen kurang melibatkan mahasiswa sehingga interaksi yang terjadi kurang dinamis, sebagian besar mahasiswa hanya mampu meniru apa yang dikerjakan dosen. Mahasiswa cenderung tidak menunjukkan minat yang baik terhadap matakuliah Algoritma dan Pemrograman. Motivasi belajar mahasiswa dalam mengikuti proses belajar mengajar juga terlihat kurang, hal ini dapat dilihat dari (1) konsentrasi mahasiswa yang tidak fokus sebab siswa banyak melakukan aktifitas diluar kegiatan belajar dan (2) waktu belajar efektif yang cenderung rendah, sebab mahasiswa dan dosen terlihat tidak memiliki ikatan kuat dalam upaya pencapain tujuan belajar.

Hasil rekapitulasi perhitungan angket monitoring evaluasi kinerja dosen pada program studi Pendidikan Teknologi Informasi dan Komputer semester genap tahun ajaran 2012/2013 yang di peroleh dari unit penjaminan mutu STKIP PGRI Pontianak menunjukkan bahwa penilaian tentang media pembelajaran yang digunakan oleh dosen masih tergolong cukup. Dalam menyampaikan materi kuliah dosen menggunakan media pembelajaran berbasis multimedia dengan program komputer yang di tampilkan melalui layar LCD proyektor. Keterbatasan peralatan yang dimiliki dan banyaknya materi yang harus disampaikan, menyebabkan metode pembelajaran kuliah di kelas menggunakan media pembelajaran ini sering kali tidak dapat dilakukan dengan baik. Dosen cenderung lebih memfokuskan pada pencapaian materi yang dibebankan pada silabus dan SAP.

Hal ini didukung oleh data hasil nilai tengah semester matakuliah Algoritma dan 
Pemrograman mahasiswa Program Studi Pendidikan Teknologi Informasi dan Komputer semester 2 angkatan 2012 kelas A sore, B pagi, dan $\mathrm{C}$ sore rata-rata 47,943 . Fakta ini menunjukkan bahwa mahasiswa belum memiliki pengetahuan yang baik. Skor ratarata nilai yang rendah ini mengindikasikan perlunya dilaksanakan inovasi pembelajaran Algoritma dan Pemrograman agar mahasiswa dapat meningkatkan hasil belajarnya dengan nilai yang lebih baik.

Setelah mengetahui berbagai faktor yang melingkupi dan menghambat tujuan pembelajaran pada Program Studi Pendidikan Teknologi Informasi dan Komputer maka peneliti ingin mencari solusi yaitu melalui pendekatan model pembelajaran blended learning untuk meningkatkan motivasi dan tingkat pemahaman mahasiswa pada mata kuliah algoritma dan pemrograman Program Studi Pendidikan Teknologi Informasi dan Komputer Sekolah Tinggi Keguruan dan Ilmu Pendidikan (STKIP) PGRI Pontianak.

\section{Schoology}

Platform Schoology dirancang oleh Jeremy Friedman, Ryan Hwang dan Tim Trinidad pasca sarjana di Washington University di St Louis, MO. Schoology.com adalah jaringan sosial untuk sekolah dan lembaga pendidikan tinggi yang berfokus pada kolaborasi, yang memungkinkan pengguna untuk membuat, mengelola, dan berbagi konten akademis. Schoology dikenal sebagai sistem manajemen pembelajaran (LMS) atau sistem manajemen kursus (CMS), platform berbasis cloud menyediakan peralatan yang diperlukan untuk mengelola sebuah kelas online.

Pada awalnya Schoology dirancang untuk berbagi catatan, kemudian dirilis secara komersial pada bulan Agustus 2009 dan tambahan fitur dan fungsionalitas terus ditambahkan. Pada Oktober 2010 layanan memiliki lebih dari 2.400 sekolah di seluruh negara di sistem dan memiliki rencana untuk membangun konten interaktif yang dapat digunakan oleh guru dan dosen untuk mendukung materi pelajaran dan memberikan lebih banyak akses ke orang tua. Schoology telah menyertakan pemberitahuan pesan teks, aplikasi mobile iPhone dan Android, integrasi dokumen Google, Google Play app, perpustakaan sumber daya bersama, dan pertanyaan untuk tes dan kuis. Pada Desember 2013 Schoology memiliki 35.000 sekolah di sistem dan lebih dari 2 juta pengguna. Schoology memiliki konsep yang menggabungkan LMS dan Social Networking.

\section{Motivasi Belajar}

Kata motivasi berasal dari bahasa Latin yaitu movere, yang berarti bergerak (move). Motivasi adalah proses yang memberi semangat, arah, dan kegigihan perilaku. Artinya, perilaku yang memiliki motivasi adalah perilaku yang penuh energi, terarah, dan bertahan lama (Santrock, 2007, p.510). Motivasi dan belajar merupakan dua hal yang saling memengaruhi. Belajar adalah perubahan tingkah laku secara relatif permanen dan secara potensial terjadi sebagai hasil dari praktik atau penguatan (reinforced practice) yang dilandasi tujuan untuk mencapai tujuan tertentu.

Motivasi berprestasi menempati kedudukan yang sangat penting, karena motivasi akan mampu mendorong perilaku mahasiswa (students behaviour) untuk bergairah, bersemangat dan rasa senang dalam belajar, sehingga pada akhirnya akan mampu memperoleh prestasi belajar yang lebih baik.

Berdasarkan paparan di atas dapat disimpulkan bahwa motivasi memiliki pengaruh terhadap hasil belajar mahasiswa. Motivasi belajar dipengaruhi oleh Self Efficacy, Locus of Control, Goal Orientation, Effort, Interest, Self Regulation, Self Esteem, Sense of self as learner yang termasuk dalam motivasi intrinsik. Sementara yang mempengaruhi motivasi dari faktor eksternal adalah : Home Support, Assessment Practice, Peer Culture, Pedagogy, Curriculum dan School Ethos (Wayne \& Ruth, 2003, p.183) .

\section{Tingkat Pemahaman}

Pada hakikatnya, pemahaman merupakan salah satu bentuk hasil belajar. Pemahaman ini terbentuk akibat dari adanya proses belajar. Pemahaman berasal dari kata dasar paham yang berarti mengerti. Pemahaman berarti mengerti benar atau mengetahui benar. Pemahaman dapat juga diartikan menguasai sesuatu dengan pikiran, maka belajar berarti harus mengerti 
secara mental makna dan filosofinya, maksud dan implikasi serta aplikasi-aplikasinya, sehingga menyebabkan mahasiswa memahami suatu situasi. Hal ini sangat penting bagi mahasiswa yang belajar adalah memahami tujuan akhir setiap pembelajaran. Pemahaman memiliki arti sangat mendasar yang meletakkan bagian-bagian belajar pada porsinya. Tanpa pemahaman, maka pengetahuan, keterampilan, dan sikap tidak akan bermakna.

Menurut Usman (2002, p.35) melibatkan pemahaman sebagai bagian dari domain kognitif hasil belajar. Pemahaman mengacu kepada kemampuan memahami makna materi. Aspek ini satu tingkat di atas pengetahuan dan merupakan tingkat berpikir yang rendah. Selanjutnya, Sudjana (2010, p.24) membagi pemahaman ke dalam tiga kategori, yakni sebagai berikut: (a) tingkat pertama atau tingkat terendah, yaitu pemahaman terjemahan, mulai dari terjemahan dalam arti sebenarnya; (b) tingkat kedua adalah pemahaman penafsiran, yakni menghubungkan bagian-bagian terdahulu dengan yang diketahui berikutnya, atau menghubungkan beberapa bagian dari grafik dengan kejadian, membedakan yang pokok dan yang bukan pokok; dan (c) pemahaman tingkat ketiga atau tingkat tertinggi, yakni pemahaman ekstrapolasi. Dengan ekstrapolasi diharapkan mampu melihat di balik yang tertulis, dapat membuat ramalan tentang konsekuensi atau dapat memperluas persepsi dalam arti waktu, dimensi, kasus, ataupun masalahnya.

Berdasarkan uraian-uraian di atas, maka dapat diketahui bahwa pemahaman marupakan salah satu bentuk pernyataan hasil belajar. Pemahaman setingkat lebih tinggi dari pengetahuan atau ingatan. Oleh karena itu, untuk meningkatkan pemahaman diperlukan proses belajar yang baik dan benar. Pemahaman mahasiswa akan dapat berkembang bila proses pembelajaran berlangsung dengan efektif dan efisien.

\section{METODE PENELITIAN}

\section{Jenis Penelitian}

Penelitian ini menggunakan desain eksperimen semu (quasi-experiment) dengan non-equivalent control group design.

\section{Waktu dan Tempat Penelitian}

Tempat penelitian berlokasi di Program Studi Pendidikan Teknologi Informasi dan Komputer Sekolah Tinggi Keguruan dan Ilmu Pendidikan (STKIP) PGRI Pontianak Provinsi Kalimantan Barat. Penelitian ini dilakukan pada bulan Maret sampai dengan April Tahun Pelajaran 2013/2014.

\section{Target/Subjek Penelitian}

Populasi dalam penelitian ini adalah mahasiswa semester 2 program studi pendidikan teknologi informasi dan komputer tahun pelajaran 2013/2014 yang berjumlah 270 mahasiswa, kemudian penentuan sampel dilakukan dengan teknik purposive sampling adalah teknik penentuan sampel dengan pertimbangan tertentu, pada penentuan sampel ini dengan pertimbangan kesesuaian jadwal perkuliahan. Sampel yang digunakan dalam penelitian ini yaitu 4 kelas dengan total mahasiswa 156 orang yang terdiri dari kelas B Pagi (34 orang) dan A Sore (44 orang) sebagai kelas Eksperimen sedangkan kelas C Pagi (32 orang) dan $\mathrm{C}$ sore (46 orang) sebagai kelas kontrol.

\section{Prosedur}

Proses penelitian diawali dengan terlebih dahulu menentukan kelompok mahasiswa yang terlibat di dalamnya. Kelompok yang digunakan dalam penelitian kuasi eksperimen mengacu pada kelas yang sudah ada terbentuk sebelumya baik sebagai kelompok kontrol maupun kelompok eksperimen (Creswell, 2012:309).

Pada penelitian ini kelompok eksperimen menggunakan model blended learning $\left(\mathrm{X}_{1}\right)$ sedangkan kelompok kontrol diberi pembelajaran menggunakan konvensional $\left(\mathrm{X}_{2}\right)$. Semua kelompok sebelumnya diberi pretest untuk membantu menetapkan ekuivalensi mereka, sebelum adanya perlakuan bersifat eksperimen.

\begin{tabular}{|lllll|}
\multicolumn{1}{ll}{ Kelompok } & Pre Test & Perlakuan & & Post test \\
\hline Eksperimen & $\mathrm{O}_{1}$ & $\longrightarrow$ & $\mathrm{X}_{1}$ & $\mathrm{O}_{2}$ \\
Kontrol & $\mathrm{O}_{3}$ & & $\mathrm{X}_{2}$ & $\mathrm{O}_{4}$ \\
\hline
\end{tabular}

Gambar 1. Desain penelitian 
Tabel 1. Output Independent Samples Test Motivasi Belajar Kelas Eksperimen dan kelas kontrol

\begin{tabular}{|c|c|c|c|c|c|c|c|c|}
\hline & & \multicolumn{7}{|c|}{ t-test for Equality of Means } \\
\hline & & \multirow[t]{2}{*}{$\mathrm{t}$} & \multirow[t]{2}{*}{ Df } & \multirow[t]{2}{*}{$\begin{array}{c}\text { Sig. } \\
\text { (2-tailed) }\end{array}$} & \multirow[t]{2}{*}{$\begin{array}{c}\text { Mean } \\
\text { Difference }\end{array}$} & \multirow[t]{2}{*}{$\begin{array}{l}\text { Std. Error } \\
\text { Difference }\end{array}$} & \multicolumn{2}{|c|}{$\begin{array}{l}95 \% \text { Confidence } \\
\text { Interval of the } \\
\text { Difference }\end{array}$} \\
\hline & & & & & & & Lower & Upper \\
\hline \multirow[t]{2}{*}{ motiv_akhir } & $\begin{array}{l}\text { Equal variances } \\
\text { assumed }\end{array}$ & 3,732 & 154 & ,000 & 5,78205 & 1,54941 & 2,72122 & 8,84289 \\
\hline & $\begin{array}{l}\text { Equal variances } \\
\text { not assumed }\end{array}$ & 3,732 & 149,099 &, 000 & 5,78205 & 1,54941 & 2,72042 & 8,84368 \\
\hline
\end{tabular}

\section{Keterangan:}

$\mathrm{O}_{1}$ : Kemampuan kelompok eksperimen sebelum diberikan perlakuan

$\mathrm{O}_{2}$ : Kemampuan kelompok eksperimen setelah diberikan perlakuan

$\mathrm{X}_{1}$ : Perlakuan dengan pembelajaran model Blended Learning

$\mathrm{X}_{2}$ : Perlakuan dengan pembelajaran model Konvensional

$\mathrm{O}_{3}$ : Kemampuan kelompok kontrol sebelum diberikan perlakuan

$\mathrm{O}_{4}$ : Kemampuan kelompok kontrol setelah diberikan perlakuan

Data, Instrumen, dan Teknik Pengumpulan Data

Untuk mengukur efektivitas model blended learning dilaksanakan pre test dan post test pada kelompok eksperimen dan kelompok kontrol. Efektivitas model blended learning dapat dilihat dari total pre test dan post test pada kelompok eksperimen dan kelompok kontrol. Data penelitian berupa skor motivasi dan skor tingkat pemahaman. Instrumen angket terdiri dari 35 butir pernyataan dengan skala Likert yang memiliki lima alternatif jawaban untuk mengukur motivasi belajar mahasiswa dan pada instrumen test untuk mengukur tingkat pemahaman mahasiswa yang terdiri dari 40 butir pertanyaan berbentuk pilihan ganda dengan lima alternatif jawaban.

\section{Teknik Analisis Data}

Penelitian ini bertujuan untuk mengetahui efektivitas model blended learning terhadap motivasi dan tingkat pemahaman mahasiswa. Kemudian dilakukan pengujian statistik untuk menguji efektivitas yang dirumuskan dalam hipotesis penelitian. Untuk menguji signifikansi perbedaan Mean lebih dari dua kelompok yang berlainan akibat penggunaan beberapa perlakuan pada suatu variabel bebas dapat dilakukan dengan uji statistik parametrik menggunakan uji -t. Sebelum melakukan uji statistik parametrik, data yang kita peroleh harus memiliki syarat-syarat dilakukannya pengujian dengan parametrik tes diantaranya adalah berdistribusi normal dan homogen. Apabila data tersebut memenuhi persyaratan dilakukan uji hipotesis dengan parametrik tes, namun apabila tidak memenuhi persyaratan maka uji hipotesis dilakukan dengan non parametrik tes.

\section{HASIL PENELITIAN DAN PEMBAHASAN}

\section{Hasil Penelitian}

Hasil analisis hipotesis 1 menggunakan data motivasi akhir kelas eksperimen dan kontrol. Data telah melewati uji persyaratan analisis dan dinyatakan telah berdistribusi normal dan homogen. Untuk menguji hipotesis 1 digunakan uji t dengan taraf signifikansi 0,05 . Rangkuman hasil perhitungan terlihat pada tabel 1 .

Berdasarkan hasil uji hipotesis pada tabel diatas dapat dilihat bahwa motivasi akhir kelas eksperimen terhadap kelas kontrol memberikan nilai signifikansi $0,000<$ signifikansi $(\alpha) 0,05$ maka terdapat perbedaan rata-rata motivasi akhir antara kelas eksperimen dan kelas kontrol sebesar 5,782. Dari hasil uji hipotesis tersebut disimpulkan bahwa terdapat perbedaan motivasi belajar mahasiswa pada mata kuliah algoritma dan pemrograman mahasiswa setelah mengikuti pembelajaran model 
Tabel 2. Output Independent Samples Test Tingkat Pemahaman Kelas Eksperimen dan kelas kontrol

\begin{tabular}{|c|c|c|c|c|c|c|c|c|}
\hline & & \multicolumn{7}{|c|}{ t-test for Equality of Means } \\
\hline & & \multirow[t]{2}{*}{$\mathrm{t}$} & \multirow[t]{2}{*}{$\mathrm{Df}$} & \multirow[t]{2}{*}{$\begin{array}{c}\text { Sig. } \\
\text { (2-tailed) }\end{array}$} & \multirow[t]{2}{*}{$\begin{array}{c}\text { Mean } \\
\text { Difference }\end{array}$} & \multirow[t]{2}{*}{$\begin{array}{l}\text { Std. Error } \\
\text { Difference }\end{array}$} & \multicolumn{2}{|c|}{$\begin{array}{l}95 \% \text { Confidence } \\
\text { Interval of the } \\
\text { Difference }\end{array}$} \\
\hline & & & & & & & Lower & Upper \\
\hline \multirow[t]{2}{*}{ motiv_akhir } & $\begin{array}{l}\text { Equal variances } \\
\text { assumed }\end{array}$ & 4,782 & 154 &, 000 & 9,93590 & 2,07786 & 5,83111 & 14,04069 \\
\hline & $\begin{array}{l}\text { Equal variances } \\
\text { not assumed }\end{array}$ & 4,782 & 144,056 &, 000 & 9,93590 & 2,07786 & 5,82886 & 14,04293 \\
\hline
\end{tabular}

blended learning dengan mahasiswa yang mengikuti pembelajaran model konvensional. Gambaran perbedaan rata-rata motivasi akhir belajar mahasiswa antara kelas eksperimen dan kontrol disajikan pada gambar 2.

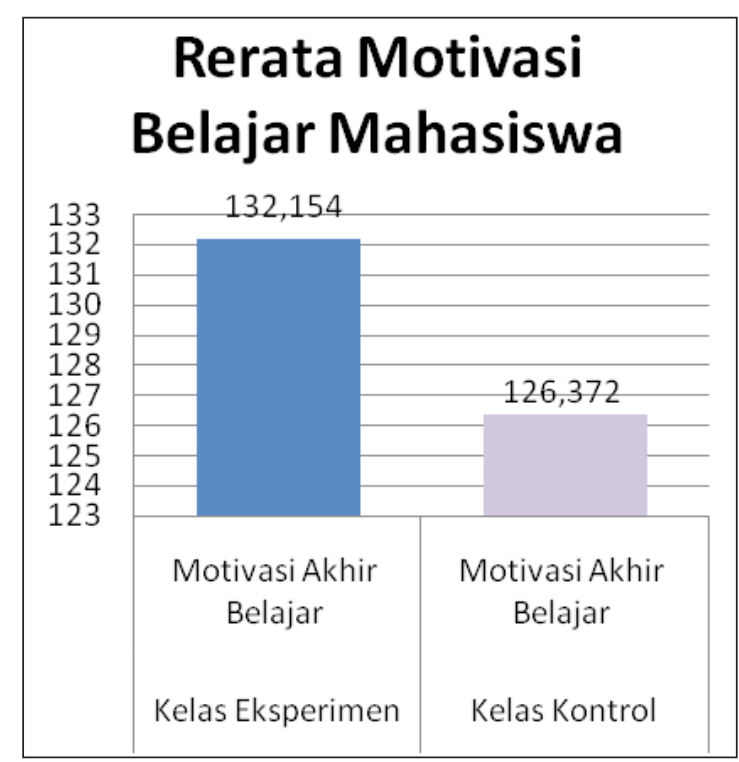

Gambar 2. Diagram Batang Rata-Rata Motivasi Akhir Belajar Kelas Eksperimen dan Kontrol

Hasil analisis hipotesis 2 menggunakan data posttest tingkat pemahaman kelas eksperimen dan kontrol. Untuk meguji hipotesis 2 digunakan uji t. Rangkuman hasil perhitungan terlihat pada tabel 2. Berdasarkan hasil uji hipotesis pada tabel 2 dapat dilihat bahwa posttest kelas eksperimen terhadap kelas kontrol memberikan nilai signifikansi $0,000<$ signifikansi $(\alpha) 0,05$ maka terdapat perbedaan rata-rata posttest antara kelas eksperimen dan kelas kontrol sebesar 9, 935. Dari hasil uji hipotesis tersebut disimpulkan bahwa terdapat perbedaan tingkat pemahaman mahasiswa pada mata kuliah algoritma dan pemrograman mahasiswa setelah mengikuti pembelajaran model blended learning dengan mahasiswa yang mengikuti pembelajaran model konvensional.

Gambaran perbedaan rata-rata posttest mahasiswa antara kelas eksperimen dan kontrol disajikan pada gambar 3 berikut ini:

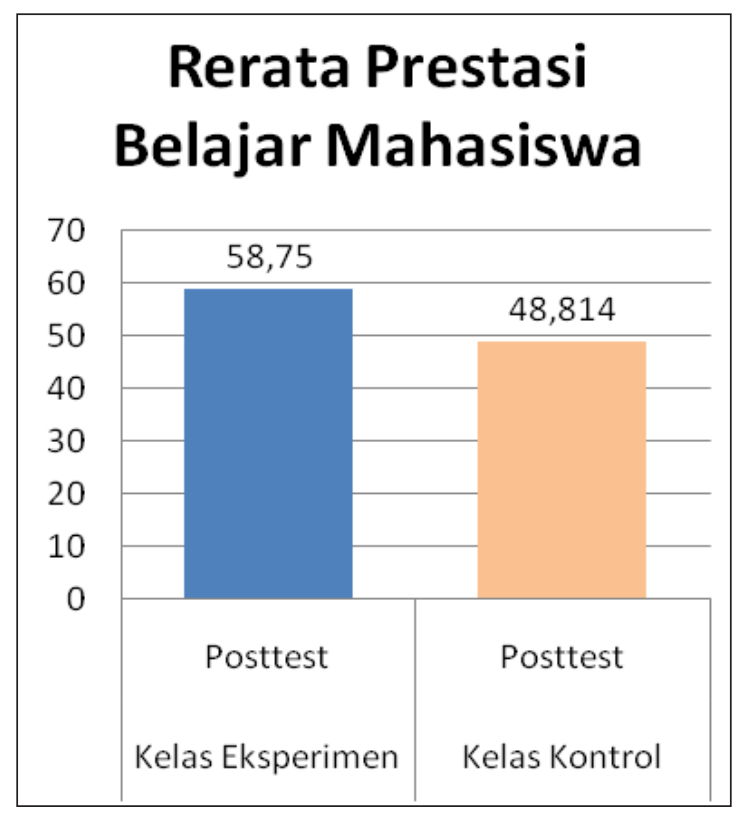

Gambar 3. Diagram Batang Rata-Rata Posttest Kelas Eksperimen dan Kontrol

Analisis hipotesisi 3 menggunakan data skor motivasi belajar sebelum dan sesudah pembelajaran blended learning. Hipotesis 3 diuji menggunakan uji t paired samples test. Terdapat peningkatan jika nilai signifikansi $<$ nilai signifikansi $(\alpha) 0,05$. Hasil hipotesis 3 menggunakan taraf signifikansi 0,05 diperoleh bahwa terdapat peningkatan motivasi belajar mahasiswa pada mata kuliah algoritma dan pemrograman akibat penerapan pembelajaran blended learning, dengan nilai signifikansi $0,000<$ nilai signifikansi $(\alpha) 0,05$. 
Tabel 3. Output Paired Samples Test Untuk Hipotesis 3

\begin{tabular}{|c|c|c|c|c|c|c|c|c|c|}
\hline & & \multicolumn{5}{|c|}{ Paired Differences } & \multirow{3}{*}{$\mathbf{t}$} & \multirow{3}{*}{ df } & \multirow{3}{*}{$\begin{array}{c}\text { Sig. } \\
\text { (2-tailed) }\end{array}$} \\
\hline & & \multirow[t]{2}{*}{ Mean } & \multirow{2}{*}{$\begin{array}{c}\text { Std. } \\
\text { Deviation }\end{array}$} & \multirow{2}{*}{$\begin{array}{c}\text { Std. Error } \\
\text { Mean }\end{array}$} & \multicolumn{2}{|c|}{$\begin{array}{c}\text { 95\% Confidence Interval } \\
\text { of the Difference }\end{array}$} & & & \\
\hline & & & & & Lower & Upper & & & \\
\hline Pair 1 & $\begin{array}{l}\text { motivasi_awal - } \\
\text { motivasi_akhir }\end{array}$ & $-11,70513$ & 9,01097 & 1,02029 & $-13,73679$ & $-9,67347$ & $-11,472$ & 77 & ,000 \\
\hline
\end{tabular}

Tabel 3. Output Paired Samples Test Untuk Hipotesis 3

\begin{tabular}{|c|c|c|c|c|c|c|c|c|c|c|}
\hline & & & \multicolumn{5}{|c|}{ Paired Differences } & \multirow{3}{*}{$\mathbf{t}$} & \multirow{3}{*}{ df } & \multirow{3}{*}{$\begin{array}{c}\text { Sig. } \\
\text { (2-tailed) }\end{array}$} \\
\hline & & \multirow{2}{*}{\multicolumn{2}{|c|}{ Mean }} & \multirow{2}{*}{$\begin{array}{c}\text { Std. } \\
\text { Deviation }\end{array}$} & \multirow{2}{*}{$\begin{array}{l}\text { Std. Error } \\
\text { Mean }\end{array}$} & \multicolumn{2}{|c|}{$\begin{array}{c}95 \% \text { Confidence Interval } \\
\text { of the Difference }\end{array}$} & & & \\
\hline & & & & & & Lower & Upper & & & \\
\hline Pair 1 & $\begin{array}{l}\text { pretest } \\
\text { posttest }\end{array}$ & - & $-30,28846$ & 5,52416 & ,62549 & $-31,53397$ & $-29,04296$ & $-48,424$ & 7 & ,000 \\
\hline
\end{tabular}

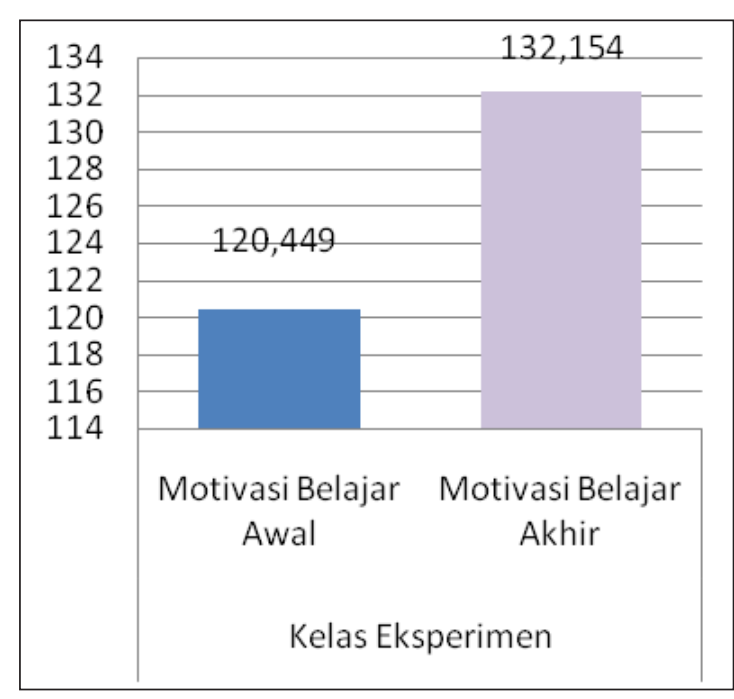

Gambar 4. Diagram Batang Rata-Rata Motivasi Belajar Sebelum dan Sesudah penerapan Blended Learning

Gambaran peningkatan rata-rata motivasi belajar disajikan pada gambar 4 .

Berdasarkan gambar 4 di atas terlihat bahwa rata-rata skor motivasi belajar yang diukur sebelum pembelajaran blended learning sebesar 120,449. Kemudian setelah diberikan pembelajaran dengan memanfaatkan blended learning sebanyak tujuh kali pertemuan, motivasi belajar diukur lagi dan diperoleh ratarata motivasi belajar 132,154 yang artinya ada peningkatan rata-rata sebesar 11,705 point. Hasil peningkatan motivasi belajar pada mata kuliah algoritma dan pemrograman akibat penerapan pembelajaran blended learning ini juga dapat dilihat pada tabel 3 .

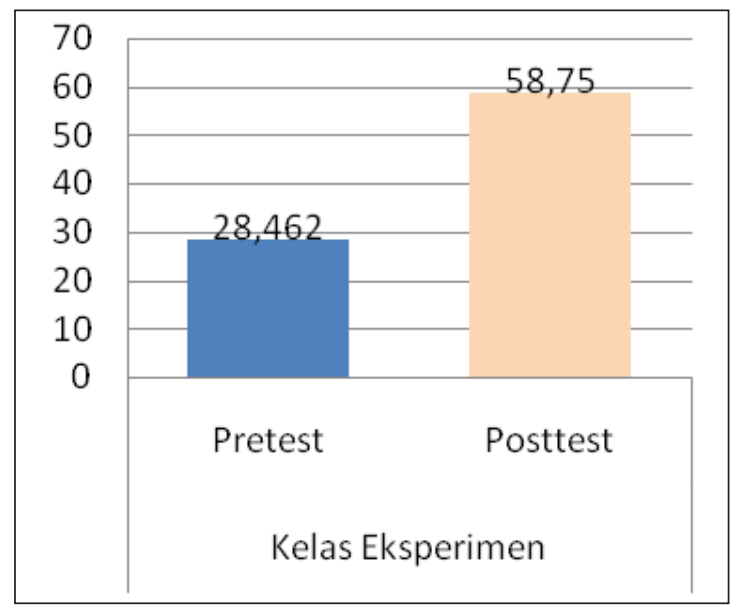

Gambar 5. Diagram Batang Rata-Rata Tingkat Pemahaman Sebelum danSesudah Penerapan Blended Learning

Hasil analisis hipotesis 4 menggunakan data skor pretest dan posttest pembelajaran blended learning. Data telah melewati uji prasyaratan analisis dan dinyatakan telah berdistribusi normal serta varians yang homogen. Hipotesis 4 di uji menggunakan uji $\mathrm{t}$ paired samples test. Hasil uji hipotesis ini dapat dilihat pada tabel 4.

Berdasarkanhasil hipotesis 4 menggunakan taraf signifikansi 0,05 diperoleh bahwa terdapat peningkatan tingkat pemahaman mahasiswa pada mata kuliah algoritma dan pemrograman akibat penerapan pembelajaran blended learning, dengan nilai signifikansi sebesar $0,000<$ signifikansi $(\alpha) 0,05$. 
Rata-rata skor tingkat pemahaman yang diukur sebelum pembelajaran blended learning sebesar 28,462. Kemudian setelah diberikan pembelajaran dengan memanfaatkan blended learning sebanyak tujuh kali pertemuan, tingkat pemahaman diukur lagi dan diperoleh rata-rata motivasi belajar 58,750 yang artinya ada peningkatan rata-rata sebesar 30,288 point. Gambaran peningkatan rata-rata tingkat pemahaman disajikan pada gambar 5 .

\section{PEMBAHASAN}

Mengacu pada tujuan penelitian analisis data diarahkan untuk menguji hipotesis agar didapat fakta empiris yang valid. Hipotesis 1 dan 2 secara esensi bertujuan untuk memberi dasar yang kuat pada pengambilan keputusan hipotesis 3 dan 4. Hal itu disebabkan karena perbedaan signifikan pada motivasi dan tingkat pemahaman mahasiswa di kedua kelas akibat pengaruh penerapan pembelajaran blended learning dibanding konvensional. Berdasarkan hasil analisis dilakukan pembahasan sebagai berikut :

Pertama, berdasarkan hasil hipotesis I bahwa terdapat perbedaan motivasi belajar mahasiswa pada mata kuliah algoritma dan pemrograman antara mahasiswa setelah mengikuti pembelajaran model blended learning dengan pembelajaran model konvensional, dimana nilai signifikansi sebesar 0,000 lebih kecil dari 0,05. Rata rata skor motivasi belajar mahasiswa kelas eksperimen sebesar 132,153. Rata - rata skor motivasi belajar mahasiswa kelas kontrol sebesar 126,371. Perbedaan rata-rata motivasi akhir antara kelas eksperimen dan kelas kontrol sebesar 5,782. Perbedaan peningkatan motivasi belajar mahasiswa pada model pembelajaran blended learning ini terlihat dari keaktifan mahasiswa yang terindikasi dengan meningkatnya partisipasi dan perhatian mahasiswa dalam proses pembelajaran. Pengaturan eksternal dari sisi pembelajaran seperti media, bahan, wacana yang disiapkan dapat menarik minat dan potensi mahasiswa untuk belajar yang menunjang munculnya atau tumbuhnya motivasi internal.

Kedua, berdasarkan hasil hipotesis II bahwa terdapat perbedaan tingkat pemahaman mahasiswa mahasiswa pada mata kuliah algoritma dan pemrograman antara mahasiswa setelah mengikuti pembelajaran model blended learning dengan pembelajaran model konvensional, dimana nilai signifikansi sebesar 0,000 lebih kecil dari 0,05 . Rata-rata tingkat pemahaman (posttest) pada kelas eksperimen adalah 58,750 dan rata-rata tingkat pemahaman (posttest) pada kelas kontrol adalah 48,814 sehingga terdapat perbedaan rata-rata tingkat pemahaman (posttest) antara kelas eksperimen dan kontrol sebesar 9,936. Perbedaan tingkat pemahaman mahasiswa tersebut terlihat pada rata-rata peningkatan tingkat pemahaman pada kelas eksperimen lebih tinggi dari pada kelas kontrol. Pada pembelajaran blended learning melengkapi dan mengatasi materi yang belum tersampaikan pada pembelajaran saat mahasiswa belajar di kelas, bermanfaat untuk mengembangkan dan menanamkan keterlibatan mahasiswa akan perkuliahan yang diadakan karena mahasiswa harus aktif mengikuti perkembangan yang terjadi di dalam kampus. Penggunaan media online berbasis web menyediakan latihan soal dan kuis yang dapat dimanfaatkan oleh mahasiswa karena feedback berupa skor yang diperoleh dapat langsung diketahui termasuk jawaban soal yang benar dan salah, hal ini dapat membantu mahasiswa untuk mengetahui kesulitan materi yang mereka hadapi sehingga memacu untuk belajar lebih giat lagi dalam meningkatkan kualitas pembelajaran.

Ketiga, berdasarkan hasil hipotesis III bahwa terdapat peningkatan motivasi belajar mahasiswa pada mata kuliah algoritma dan pemrograman akibat penerapan pembelajaran blended learning, dimana nilai signifikansi sebesar $0,000<0,05$. Rata-rata skor motivasi awal sebelum pembelajaran blended learning sebesar 120,449, kemudian setelah diterapkan pembelajaran model blended learning sebanyak tujuh kali pertemuan ratarata skor motivasi belajar sebesar 132,154, terdapat peningkatan rata-rata sebesar 11,705. Secara umum penggunaan model blended learning pada proses pembelajaran berpengaruh signifikan terhadap peningkatan motivasi belajar mahasiswa. Pembelajaran dengan blended learning ini memberikan ruang yang lebih luas kepada mahasiswa 
untuk melakukan eksplorasi kemampuan dan kemandirian yang selama ini terpusat pada kegiatan pembelajaran dalam kelas. Blended learning memadukan pembelajaran tatap muka dengan online learning yang menimbulkan interaksi dinamis antara mahasiswa dengan dosen dan mahasiswa dengan mahasiswa serta pennggunaan metode pembelajaran yang variatif dan disukai oleh mahasiswa akan meningkatkan motivasi belajar mahasiswa.

Keempat, berdasarkan hasil hipotesis IV bahwa terdapat peningkatan tingkat pemahaman mahasiswa pada mata kuliah algoritma dan pemrograman akibat penerapan pembelajaran blended learning, dimana nilai signifikansi $0,000<(\alpha) 0,05$. Ratarata skor tingkat pemahaman yang diukur sebelum pembelajaran blended learning sebesar 28,462. Kemudian setelah diberikan pembelajaran dengan memanfaatkan blended learning sebanyak tujuh kali pertemuan, tingkat pemahaman diukur lagi dan diperoleh rata-rata motivasi belajar 58,750 yang artinya ada peningkatan rata-rata sebesar 30,288. Model pembelajaran blended learning merujuk pada penggunaan internet untuk mengirimkan serangkaian solusi yang dapat meningkatkan pengetahuan dan keterampilan. Mengoptimalkan peran komputer sebagai sarana untuk menampilkan dan merekayasa teks, grafik, dan suara dalam sebuah tampilan yang terintegrasi. Pemanfaatan teknologi informasi dapat melatih mahasiswa untuk belajar bagaimana belajar (learn how to learn). Dalam pembelajaran blended learning akan banyak sumber belajar yang harus di akses oleh mahasiswa, karena sumber-sumber tersebut tidak hanya terbatas pada sumber belajar yang dimiliki oleh dosen. Hal tersebut juga harus di dukung oleh kemampuan dosen dalam merancang sumber-sumber belajar mana saja yang dapat diakses untuk mengkombinasikan dengan buku, multimedia dan sumber belajar lain. Pelaksanaan pembelajaran juga efisien dari segi waktu karena pemberian materi yang sifatnya mandiri bagi mahasiswa akan dialokasikan waktunya pada e-learning, sementara materi yang memerlukan penjelasan khusus akan dialokasikan waktu tatap muka. Pembelajaran tatap muka juga digunakan untuk melakukan refleksi pembelajaran e-learning antar mahasiswa dan dosen. Mahasiswa akan belajar sesuai dengan gaya belajar dan kecepatan masing-masing dibawah bimbingan dosen yang berperan mendorong dan melengkapi seluruh rangkaian proses pembelajaran.

\section{SIMPULAN DAN SARAN}

\section{Simpulan}

Berdasarkan hasil penelitian yang telah dikemukakan pada bab sebelumnya, dapat disimpulkan sebagai berikut:

Pertama, motivasi belajar mahasiswa Program Studi Pendidikan Teknologi Informasi dan Komputer STKIP PGRI Pontianak untuk mata kuliah Algoritma dan Pemrograman memiliki perbedaan signifikan antara kelas yang menggunakan model blended learning dengan kelas yang menggunakan model konvensional.

Kedua, tingkat pemahaman mahasiswa Program Studi Pendidikan Teknologi Informasi dan Komputer STKIP PGRI Pontianak untuk mata kuliah Algoritma dan Pemrograman memiliki perbedaan signifikan antara kelas yang menggunakan model blended learning dengan kelas yang menggunakan model konvensional.

Ketiga, motivasi belajar mahasiswa Program Studi Pendidikan Teknologi Informasi dan Komputer STKIP PGRI Pontianak untuk mata kuliah Algoritma dan Pemrograman mengalami peningkatan secara signifikan disebabkan penerapan model blended learning.

Keempat, tingkat pemahaman mahasiswa Program Studi Pendidikan Teknologi Informasi dan Komputer STKIP PGRI Pontianak untuk mata kuliah Algoritma dan Pemrograman mengalami peningkatan secara signifikan disebabkan penerapan model blended learning

\section{Saran}

Dari hasil penelitian dan pembahasan yang telah diuraikan sebelumnya, ada beberapa hal yang dapat disarankan diantaranya adalah:

Pertama, model pembelajaran blended learning telah terbukti dapat meningkatkan motivasi dan tingkat pemahaman mahasiswa. 
Oleh karena itu pihak kampus senantiasa perlu mendorong penerapan model ini lewat pelatihan dosen dan menyediakan fasilitas yang menunjang terlaksananya model pembelajaran tersebut.

Kedua, kebutuhan akan teknologi informasi merupakan keharusan dalam pembelajaran modern. Oleh karena itu berbagai upaya peningkatan pembelajaran khusus nya mahasiswa Studi Pendidikan Teknologi Informasi dan Komputer yang dilakukan oleh seluruh pihak terkait.

\section{DAFTAR PUSTAKA}

Abdul, K. (2012). Algoritma dan pemrograman menggunakan java. Yogyakarta: Andi offset.

Ahmed, et.al. (2008). Blended e-learning design : Discussion of cultural issues. Journal of Cyber Society and Education. 17-32

Antonius, R.C. (2010). Algoritma dan pemrograman dengan bahasa $c$. Yogyakarta: Andi offset.

Barbara, S., et al. (2008). Vienna E-Lecturing (VEL): Learning how to learn selftregulated in an internet-based blanded learning setting. International journal on e-learning.

Bishop, G. (1989). Alternative Strategies foe Education, London, Mc Millan Publisher Ltd, dalam Menyemai benih teknologi pendidikan, Yusufhadi Miarso, Kencana, Jakarta.

Dagdilelis, V., Satratzemi, M., and Evangelidis, G. (2004). Introducing secondary education student to algoritms and. Education and information technologies 9:2, 159-173. Kluwer academic publishers. Manufactured in the Netherlands.

Dankel, Muijs. (2004). Doing Quantitative Research in Education, British library.

Direktorat Jendral Pendidikan Tinggi. (2008). Pengembangan Kurikulum Berbasis Kompetensi Pendidikan Tinggi.
Driscoll, M., \& Carliner, S. (2005). Advanced web-based training strategies:

UnlockingInstructionally sound online learning. San Francisco: John Wiley \& Sons, Inc.

Fenton, D. \& Watkins, B. W. (2010). Fluency in distance learning. Charlotte, NC: Information age publishing, Inc

Fyans, Leslie J., \& Jr., Martin L. Maehr. (1990). School Culture, Student Ethnicity, and Motivation ED327 947 . Urbana, Illinois: The National Center for School Leadership

Graham, C. R. (2006). Blended learning systems: Definition, current trends, and future directions. Dalam C. J. Bonk \& C. R. Graham (Eds), The Handbook of blended learning: Global perspectives, local designs (pp. 3-21). San Francisco, CA: John Wiley \& Sons, Inc.

Hadjerrouit, S. (2007). A Blended learning model in java programming: A designbased research approach. Proceeding of the 2007 computer science and IT education conference, 283-308.

Hadjerrouit, S. (2008). Towards a Blended Learning Model for Teaching and Learning Computer Programming: A Case,Study,( Informatics in Education: Institute of Mathematics and Informatics, Vilnius, Vol. 7, No. 2, 181-210), Journal.

Hamzah B.Uno.(2013). Teori motivasi dan pengukurannya. Jakarta : Bumi Aksara

Harlen, W. and Crick, R.D. (2003). Testing and motivation for learning. Graduate School of Education, University of Bristol, 35 Berkeley Square, Bristol BS8 1JA, UK, Assessment in Education, Vol. 10, No. 2.

Heinze, A. (2008). Blended learning : An interpretive action reseach study. Disertasi doktor, tidak diterbitkan, University of Salford, Salford, UK

Heinze, A. \& Procter. (2006). Online communication and information 
technology education. Journal of Information Technology Education. (5), 236.

Jere, Brophy (2004). Motivating Students to Learn. Author, Edition, reprint, revised. Publisher, Taylor \& Francis, ISBN, $0805847723,9780805847727$.

Kaye \& Thorne. (2003). Blended learning : how to integrate online and traditional learning. Great Britain and the United States: Kogan Page Limited.

Margolis, H., \& McCabe, P. (2004). Selfefficacy: A key to improving the motivation of struggling learners. The Clearing House, 77, 241-249.

Moh, Sjukani. (2004). Algoritma \& Struktur Data dengan $C$, $C++$, dan Java. Jakarta: Mitra Wacana Media.

Moh. Usman, U. (2002). Menjadi guru profesional. Bandung: PT. Remaja Rosdakarya

Mortera-Gutierrez, F. (2005). Faculty best practices using blended learning in e-learning and face-to-face instruction. 20th Annual Conference on Distance Teaching and Learning. The Board of Regents of the University of Wisconsin System.

Nana, S. (2010). Evaluasi proses dan hasil pembelajaran. Jakarta: Bumi Aksara

Patron, H., \& Lopez, S. (2011). Student effort, consistency, and online performance. The Journal of Educator Online, Vol 8 (2).

Prawiradilaga, Dewi Salma. (2007). Prinsip disain pembelajaran : Instructional Design Principles. Jakarta: Kencana.

Purwanto. (2013). Evaluasi hasil belajar. Yogyakarta: Pustaka belajar.

Ruiz, J.G., Mintzer, M.J. and Leipzig, R.M. (2006). The Impact of E-Learning in Medical Education. Academic Medicine, 81(3), 207-212.
Rusman, Deni, K., \& Cepi, R. (2012). Pembelajaran berbasis teknologi Informasi dan komunikasi. Mengembangkan profesional guru. Jakarta : Kharisma putra utama offset

Santrock, J.W. (2007). Educational psychology. New York: McGraw-Hill.

Schunk, D.H., Pintrich, P.R., \& Meece, J.L. (2012). Motivation in Education: Theory, Research, and application. Third Edition, Pearson Education, Upper Saddle River, New Jersey.

Slemer, S. (2005). Use blended learning to increase learner engagement and reduce training cost

Seok, S. (2008). Teaching aspect on e-learning. International journal on e-learning.

Sharpe, Rhona et.al. (2006). The undergraduate experience of blended e-learning : A review of Uk literature and practice.

Susilana, R. \& Riyana. (2009). Media pembelajaran: hakikat, pengembangan, pemanfaatan, dan penilaian. Bandung: Wacana Prima.

Sutratinah, \& Tirtonegoro. (2001). Penelitian Hasil Belajar Mengajar. Surabaya: Usaha Nasional.

Djamarah, Syaiful. Bahri.(1994). Prestasi belajar dan kompetensi guru. Surabaya: Usaha Nasional.

Tam, M. (2000). Constructivism, instructional design, and technology: Implication for transforming distance learning. Education technology, Volume 3 number 2.

Team Schoology. (2013). Schoology instructor guide. Lake Mills High School.

Thorne, K. (2003). Blended learning: How to integrate online and traditional learning. London: Kogan Page.

Walberg, H.J. \& Tsai, S.L. (1983). Matthew effects in education. American educational research journal Vol. 20, No. 3, Pp. 359-373. 
Wayne, H. \& Ruth, D.C. (2003) Testing and Motivation for Learning, Graduate School of Education, Assessment in Education, Journal Assessment in Education, Vol.10, No.2.

Winataputra, (2008), Teori belajar dan pembelajaran, Universitas Terbuka, Jakarta.

Winkel, W.S. (1999). Psikologi pengajaran. Jakarta : PT. Grasindo.

Wowo, S.K. (2013). Filsafat pendidikan teknologi vokasi dan kejuruan. Bandung: Alfabeta.
Xiaojing Liu, Xiaoying Wang \& Rui Wang. (2013). Application of blended learning in data structures and algorithms course teaching. International conference on education technology and information system. Department of computer technology and application, Qinghai university, Xining, 810016, China.

Zaenal, Abidin, "Motivasi dalam strategi pembelajaran dengan pendekatan ARCS",(Jurnal Fakultas Agama Islam Universitas Muhammadiyah Surakarta, Vol.XVIII), 43. 